\title{
LONG-TERIM RESULTS AFTER REOPERATION FOR FAILED ANTIREFLUX PROCEDURES
}

Claude Deschamps, MD

Victor F. Trastek, MD

Mark S. Allen, MD

Peter C. Pairolero, MD

Julie O. Johnson, RN

Dirk R. Larson, MS
From January 1960 to June 1995, 185 patients underwent reoperation without esophageal resection for symptoms of recurrent gastroesophageal reflux disease. There were 102 men and 83 women. Median age was 58 years (range 20 to 84 years). A single previous antireflux operation had been performed in 147 patients, two in 33 , and three in 5 . The median interval between the reoperation and the previous operation was 36 months (range 1 to 291 months). Indications for reoperation were symptoms in 184 patients and a large paraesophageal hernia in one patient. The surgical approach was by means of a thoracotomy in 133 patients $(71.9 \%)$, laparotomy in $27(14.6 \%)$, and a thoracoabdominal incision in $25(13.5 \%)$. A Nissen fundoplication was performed in 107 patients $(\mathbf{5 7 . 8 \% )}$, Belsey fundoplication in $47(25.4 \%)$, truncal vagotomy and antrectomy with Roux-en-Y reconstruction in $17(9.2 \%)$, anatomic hernia repair in $12(6.5 \%)$, and Hill gastropexy in $2(1.1 \%)$. A Collis gastroplasty was added to the fundoplication in 116 patients $(62.7 \%)$, and a pyloroplasty was performed in $17(9.2 \%)$. There was one operative death $(0.5 \%)$. Complications occurred in 47 patients $(25.4 \%)$. Median postoperative hospitalization was 9 days (range 5 to 58 days). Follow-up was complete in 156 patients $(84.3 \%)$ and ranged from 3 to 283 months (median 44 months). Improvement occurred in 137 patients $(87.8 \%)$. Functional results were classified as excellent in 65 patients $(41.6 \%)$, good in $29(18.6 \%)$, fair in $43(27.6 \%)$, and poor in 19 $(\mathbf{1 2 . 2 \%})$. No single operative approach or procedure proved to be functionally superior. We conclude that reoperation with esophageal preservation after a failed antireflux procedure will result in significant functional benefit and can be performed with low mortality and acceptable morbidity. The type of repair should be tailored to the individual patient. ( $J$ Thorac Cardiovasc Surg 1997;113:545-51)
$\mathrm{P}$ imary surgical treatment for gastroesophageal reflux disease (GERD) is associated with a longterm success rate of $80 \%$ to $90 \%,{ }^{1-3}$ whereas reoperations are associated with a success rate varying from $42 \%$ to $94 \% .^{4-13}$ Factors associated with failure and recurrence are not well known, and the optimal

From the Sections of General Thoracic Surgery and Biostatistics, Mayo Clinic and Mayo Foundation, Rochester, Minn.

Read at the Seventy-sixth Annual Meeting of The American Association for Thoracic Surgery, San Diego, Calif., April 28-May 1, 1996.

Received for publication May 6, 1996; revisions requested June 24, 1996; revisions received August 23, 1996; accepted for publication Nov. 8, 1996.

Address for reprints: Claude Deschamps, MD, Section of General Thoracic Surgery, Mayo Clinic and Mayo Foundation, 200 First St., SW, Rochester, MN 55905.

Copyright (C) 1997 by Mosby-Year Book, Inc.

$0022-5223 / 97 \$ 5.00+0 \quad \mathbf{1 2 / 6 / 7 9 1 8 1}$ surgical treatment of recurrences is debated. To evaluate long-term functional results, we retrospectively reviewed our experience in patients who underwent reoperation without esophageal resection for recurrent reflux or obstruction symptoms.

\section{Patients and methods}

From January 1960 to June 1995, 2079 patients underwent an antireflux procedure at the Mayo Clinic. Of these, 185 patients $(8.9 \%)$ had reoperation without esophageal resection. The records of these 185 patients were analyzed for age, gender, symptoms, operative morbidity and mortality, and factors affecting late functional outcome. Data were acquired from questionnaires sent to patients and referring physicians and from visits to the outpatient clinic. Operative deaths included patients who died within the first 30 days after operation and those who died later but during the same hospitalization. Functional status was considered excellent if the patient was without symptoms and not receiving medication; status was considered good if the patients had mild symptoms without medication or 
Table I. Complications

\begin{tabular}{lr}
\hline \multicolumn{1}{c}{ Complications } & No. $(\%)$ \\
\hline Leak & $12(6.5)$ \\
Atelectasis/pneumonia & $9(4.9)$ \\
Arrhythmia & $9(4.9)$ \\
Delayed gastric emptying & $4(2.1)$ \\
Wound infection & $3(1.6)$ \\
Splenic injury & $2(1.1)$ \\
Acute gastric herniation & $1(0.5)$ \\
Bleeding & $1(0.5)$ \\
Other & $6(3.1)$ \\
\hline
\end{tabular}

needed only one postoperative dilatation; it was fair if symptoms were controlled with medication or periodical dilatations; it was poor if the patient's condition was unimproved after surgery or warranted reoperation because of a complication. ${ }^{7}$ All hernias were classified according to the method of Skinner. ${ }^{14}$

Two-way contingency tables were used to determine which clinical factors were associated with the functional outcome. Tests for independence were carried out with an exact Wilcoxon test for ordered categoric variables. ${ }^{15}$ The relationship between the functional result and the clinical factors was analyzed further by fitting a logistic regression model. ${ }^{16}$ In this case, the outcome variable was treated as binary, with the categories of excellent, good, fair, and poor. The risk of reoperation was estimated by computing Kaplan-Meier survival curves. ${ }^{17}$ Estimates were computed for the overall patient sample, as well as for subgroups that were based on clinical risk factors. Patient groups exhibiting different levels of a particular risk factor were compared by means of the log-rank test. ${ }^{18}$ The threshold for statistical significance for all tests was set at $p=0.05$.

Clinical findings. There were 102 men $(55.1 \%)$ and 83 women $(44.9 \%)$. The median age at the time of reoperation was 58 years (range 20 to 84 years). One hundred forty-seven patients had one previous antireflux procedure, 33 had two, and 5 had three. Previous antireflux operations included 140 transabdominal Nissen fundoplications, 37 anatomic hernia repairs, 19 Belsey fundoplications, 14 transthoracic Nissen fundoplications, 10 Hill gastropexy, 7 Angelchik prosthesis, and 1 unknown. Median time between the most recent antireflux operation and reoperation at our institution was 36 months (range 1 to 291 months). Thirty-eight patients had previous surgery for peptic ulcer disease. Of these, 26 had truncal vagotomy and pyloroplasty, 5 had truncal vagotomy and gastrojejunostomy, 4 had truncal vagotomy and antrectomy, and 3 had highly selective vagotomy. Indications for surgery were recurrent reflux symptoms in 134 patients $(72.4 \%)$, esophageal obstruction in $50(27.0 \%)$, and a large paraesophageal hernia in $1(0.06 \%)$. Duration of symptoms ranged from 1 to 40 years (median 2 years). Pyrosis was present in 135 patients $(80.0 \%)$, dysphagia in $124(67.0 \%)$, regurgitation in $94(50.8 \%)$, pain in $93(50.3 \%)$, and previous episodes of aspiration in $35(18.9 \%)$. Esophageal dilatation had been performed at least once in 56 patients (30.3\%) before reoperation. Weight loss was observed in 15 patients (median $11.4 \mathrm{~kg}$, range 2.3 to $34.1 \mathrm{~kg}$ ). Barium roentgenographic examination of the esophagus was per- formed in 179 patients (96.8\%), esophagoscopy in 174 (94.1\%), esophageal manometry in $152(82.2 \%)$, and a $\mathrm{pH}$ study in $42(22.7 \%)$. Barium swallow analysis showed a hiatal hernia in 143 patients $(79.9 \%)$ and a stricture in 40 $(22.3 \%)$. Esophagitis or a stricture was present at esophagoscopy in 130 patients $(74.7 \%)$, and Barrett's disease was documented histologically in $29(16.7 \%)$. Low amplitude peristalsis of the body of the esophagus was shown on manometry in 38 patients $(25 \%)$. The lower esophageal sphincter was hypotensive in 95 patients $(62.5 \%)$ and hypertensive in $6(3.9 \%)$. Thirty-three patients $(78.6 \%)$ had a positive $\mathrm{pH}$ study. After preoperative evaluation, 169 patients $(91.4 \%)$ were considered to have a hiatal hernia. One hundred forty-eight patients had a type I hernia, 8 had type II, 9 had type III, and 4 had type IV.

The surgical approach was through a left thoracotomy in 133 patients (71.9\%), laparotomy in $27(14.6 \%)$, and a thoracoabdominal incision in $25(13.5 \%)$. Operative findings included a recurrent hernia in 116 patients $(62.7 \%)$, a perigastric fundoplication in $22(11.9 \%)$, a tight fundoplication or hiatal closure in $21(11.4 \%)$, a disrupted fundoplication in $19(10.3 \%)$, or a combination of the previously listed findings in $7(3.8 \%)$. A Nissen fundoplication was performed in 107 patients $(57.8 \%)$, Belsey fundoplication in $47(25.4 \%)$, truncal vagotomy and antrectomy with Roux-en-Y reconstruction in 17 (9.2\%), anatomic hernia repair in 12 (6.5\%), and Hill gastropexy in $2(1.1 \%)$. An uncut Collis gastroplasty was added to the fundoplication in 85 patients; a cut Collis gastroplasty in 31 ; a pyloroplasty in 17; splenectomy in 2 ; excision of epiphrenic diverticulum in 2; and a truncal vagotomy, excision of gastric ulcer, and cricopharyngeal myotomy in one patient each.

\section{Results}

Complications occurred in 47 patients $(25 \%)$ (Table I). There was one operative death (mortality $0.5 \%$ ). Cause of death was a leak and secondary sepsis after truncal vagotomy, antrectomy, and Roux-en-Y reconstruction. Median postoperative hospitalization was 9 days (range 5 to 58 days). All 184 operative survivors were followed up for at least 3 months. Fifteen patients (8.2\%) needed esophageal dilatation within the first 3 months of reoperation. Functional results at 3 months were classified as excellent in 161 patients $(87.0 \%)$, good in 13 $(7.0 \%)$, fair in $7(3.8 \%)$, and poor in $3(1.6 \%)$. Long-term follow-up was complete in 156 patients $(84.3 \%)$ and ranged from 3 to 283 months (median 31 months). Overall, 137 patients $(87.8 \%)$ had improved conditions. Long-term functional results (Table II) were classified as excellent in 65 patients (41.6\%), good in 29 (18.6\%), fair in $43(27.6 \%)$, and poor in $19(12.2 \%)$.

During follow-up, 20 patients $(10.8 \%)$ required another operation for problems related to recurrent 
or persistent GERD or gastric stasis a median of 28 months after the antireflux procedure (range 0 to 214 months). Esophageal resection was performed in 6 patients $(3.3 \%)$, fundoplication in $5(2.7 \%)$, pyloroplasty in $4(2.2 \%)$, feeding jejunostomy in 4 $(2.2 \%)$, and antrectomy with Roux-en-Y reconstruction in $1(0.05 \%)$. Resection was for a nondilatable stricture in four patients and high-grade dysplasia in two with Barrett's disease.

Overall analysis showed that preoperative factors including gender, age, symptoms, type or number of previous operations, preoperative dilatation, presence of Barrett's disease, and endoscopy, manometry, barium swallow, and $\mathrm{pH}$ findings did not affect late functional results. Likewise, the surgical approach and type of reoperative procedure did not affect late functional results; however, the finding of a perigastric fundoplication at reoperation did correlate with a poor result $(p<0.05)$. Additionally, if early postoperative dilatation was required, this adversely affected the late functional result $(p<$ 0.05 ). Postoperative morbidity was not affected by the number of previous procedures $(p=0.08)$. Overall, estimated 5-, 10-, and 20-year freedom from another reoperation for recurrent or persistent GERD or related complications was $88.0 \%(95 \%$ confidence interval [CI], $81.3 \%$ to $94.5 \%$ ), $86.3 \%$ $(95 \% \mathrm{CI}, 78.5 \%$ to $93.6 \%)$ and $69.1 \%(95 \% \mathrm{CI}$, $50.0 \%$ to $87.7 \%$ ), respectively (Fig. 1).

\section{Discussion}

Poor outcome after an antireflux procedure can result from a variety of causes. The most common is persistent or recurrent reflux resulting from an anatomic recurrence of a hiatal hernia, a perigastric fundoplication, an incompetent repair, or a partial or complete disruption of the repair. Late outcome is also dependent on a number of other variables including the functional and anatomic integrity of the stomach and esophagus, previous attempts at correction, and other associated conditions such as chronic obstructive pulmonary disease or severe obesity. ${ }^{19}$ Other complications ${ }^{20,21}$ which can contribute to a poor outcome include esophageal obstruction, gastric stasis, dumping, severe gas-bloat syndrome, inability to belch or vomit, and diarrhea.

The type and intensity of postoperative symptoms are variable. ${ }^{21}$ The majority of our patients $(72.4 \%)$ had persistent or recurrent reflux symptoms. The remaining patients $(27.6 \%)$ had esophageal obstruction, and only one was without symptoms. The presence of dysphagia or other symptoms not clearly
Table II. Long-term functional results in 156 patients

\begin{tabular}{lcccc}
\hline \multicolumn{1}{c}{ Symptoms } & Excellent & Good & Fair & Poor \\
\hline None & 65 & - & - & - \\
Reflux & - & 5 & 17 & - \\
Dysphagia & - & 20 & 21 & 15 \\
Gastric stasis & - & - & 3 & 4 \\
Dumping & - & 4 & 2 & - \\
Total $(\%)$ & $65(41.6)$ & $29(18.6)$ & $43(27.6)$ & $19(12.2)$ \\
\hline
\end{tabular}

caused by reflux suggests either a motility disorder or an obstructing lesion. The total number of patients seen with symptoms after previous surgical treatment for GERD is unknown. At our institution the ratio of patients who had primary repair to those who had reoperation without resection was 11.2 to 1 .

The operative records of previous operations should be carefully reviewed ${ }^{19}$. when planning a reoperation. The approach, operative findings, difficulties encountered, and the type of repair are essential information. Preoperative evaluation should also include barium upper gastrointestinal roentgenographic examination, esophagoscopy, esophageal motility, and $\mathrm{pH}$ monitoring. Barium swallow analysis is most useful to delineate gastric anatomy. Esophagoscopy allows histologic evaluation of the mucosa and determination of whether a stricture is dilatable. Manometry can be difficult to interpret after a tight wrap and can mimic findings of achalasia or diffuse esophageal spasm. Nevertheless, it helps decide whether a total or partial fundoplication should be performed, depending on the quality and amplitude of esophageal peristalsis. If a question exists whether acid reflux is present, $\mathrm{pH}$ monitoring can be of help. Symptoms suggesting delayed or accelerated gastric emptying should prompt a radionuclide gastric emptying study.

The choice of which procedure to perform can be difficult. Although no ideal operation exists, the goal of repair remains anatomic reduction of the hernia and a competent lower esophageal sphincter. The choice of reoperation should be individualized, ${ }^{22}$ taking into consideration the state of the esophagus (stricture, motility disorder, fistula), the presence of delayed gastric emptying, and previous repairs and approaches. Our preferred approach is by means of a thoracotomy when reoperating on patients with GERD. It allows optimal exposure of the thoracic portion of the esophagus and can be extended into the abdomen as a thoracoabdominal incision to improve exposure, particularly if a more extensive 


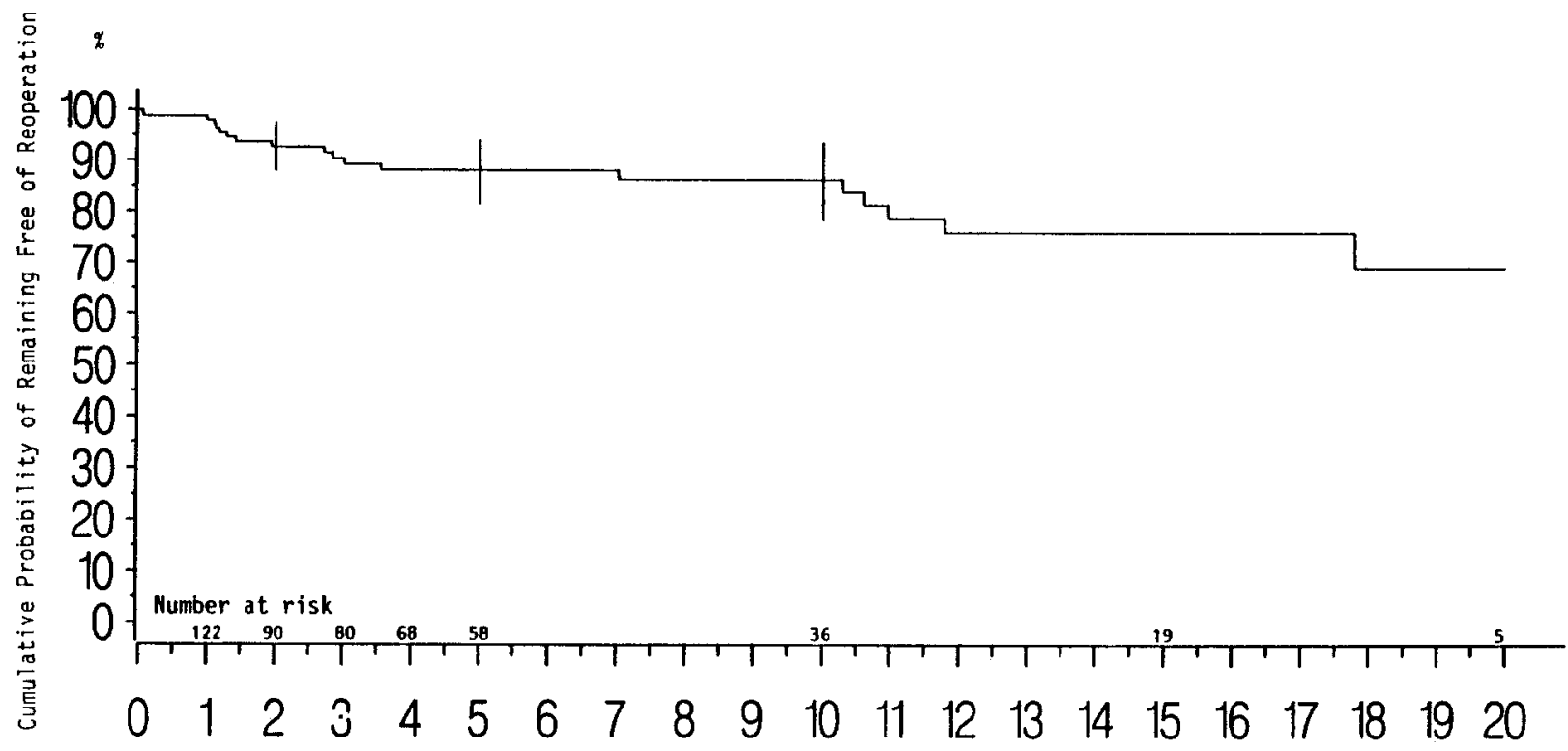

Years From First Reoperation

With 95 confidence Intervals

Fig. 1. Actuarial cumulative probability of reoperation after the first reoperation for failed antireflux procedure.

procedure is needed, such as an antrectomy with Roux-Y reconstruction or an esophageal resection. Alternatively, the diaphragm can be divided to facilitate exposure. The old repair should be taken down, and the integrity of the esophagus, esophagogastric junction, and stomach should be assessed. In situations where extensive damage of the vagal fibers is suspected, a pyloroplasty should be added to the antireflux procedure. Deciding between a total or a partial fundoplication is more a question of personal choice when the propulsive characteristics of the esophagus are within normal limits. If peristalsis is of weak amplitude, however, a partial fundoplication should be performed. If the esophagus is short, a cut-Collis gastroplasty is done to provide an additional 2 to $3 \mathrm{~cm}$ of neoesophagus, which allows the repair to be placed under the diaphragm without tension. ${ }^{23}$ The uncut-Collis gastroplasty has been used in our experience to provide a secure anchor for the repair. ${ }^{3,24,25}$ The crura should be approximated with heavy nonabsorbable sutures, and the repair should be reduced completely under the diaphragm.

Vagotomy and antrectomy with Roux-Y reconstruction was performed mostly as a tertiary proce- dure when the fundus was inadequate for any type of repair. Despite the potential disadvantage of regurgitation and aspiration of a bland refluxate, ${ }^{10}$ it remains a viable alternative to extensive resection. ${ }^{13,26,27}$

Although not reviewed in this article, the question of when to resect is critical. In the report by Little and associates, ${ }^{7}$ resection was more likely to be needed after multiple operations. In contrast, our data suggest that late failure after reoperation was not a function of the number of previous repairs. Rather, failure in our patients occurred most commonly because of obstruction rather than reflux (Table II), and the need for postoperative dilatation within 3 months of reoperation served as an early warning of late failure. This finding would suggest that, even after multiple repairs, patients should be individualized, and we would favor resection only in patients with obstructive symptoms or when the quality of the tissue at the gastroesophageal junction is such that safe restoration of the lower esophageal sphincter is compromised. ${ }^{28}$ Every effort should be made to retain the native esophagus when the process appears reversible.

Functional results after reoperative antireflux sur- 
Table III. Other series ${ }^{4-8,10-13}$

\begin{tabular}{|c|c|c|c|c|c|c|c|}
\hline Author & Year & Patients & Incision & Repair & Mortality & Follow-up (yr) & Results* \\
\hline Hill & 1979 & 25 & A & Gastropexy & 0 & 2 & $91 \%$ \\
\hline Henderson & 1981 & 121 & TA & Other & 0 & 2.5 & $94 \%$ \\
\hline Leonardi & 1981 & 25 & A & Variousł & 0 & 2.8 & $95 \%$ \\
\hline Little & 1986 & 61 & $\mathrm{~T}, \mathrm{~A}$ & Varioust & $4.9 \%$ & 3.8 & $42-85 \%$ \\
\hline Pearson & 1987 & 118 & $\mathrm{~T}$ & Other§ & 0 & - & $80 \%$ \\
\hline Fékété & 1992 & 50 & A & Various & 0 & 3.5 & $86 \%$ \\
\hline Skinner & 1992 & 117 & $\mathrm{~T}, \mathrm{~A}$ & Various $\ddagger$ & $1.7 \%$ & - & - \\
\hline Ellis & 1994 & 36 & $\mathrm{~T}$ & Otherף & 0 & 6.7 & $70 \%$ \\
\hline Stein & 1996 & 71 & - & Various & $1.4 \%$ & 3.5 & $86 \%$ \\
\hline Mayo & 1996 & 185 & $\mathrm{~T}, \mathrm{TA}, \mathrm{A}$ & Various & $0.5 \%$ & 3.7 & $60 \%$ \\
\hline
\end{tabular}

A, Abdomina; $T A$, thoracoabdominal; $T$, thoracic.

Excellent and good.

†T Total fundoplication, gastroplasty.

Includes esophageal resection.

\&Partial fundoplication, gastroplasty.

IVagotomy, antrectomy, Roux-en-Y.

gery deteriorate with time as shown by an increased rate of subsequent operations 20 years later as compared with only 5 years later. This increased late failure rate underlines the importance of adhering to strict principles of antireflux surgery at the initial operation.

The use of laparoscopic techniques for treatment of GERD and hiatal hernia ${ }^{29}$ should be viewed with great caution for reoperative hiatal hernia surgery. ${ }^{30}$ Currently we do not recommend laparoscopy for redo hiatal hernia surgery. Only long-term evaluation will provide sufficient information regarding morbidity and functional results on which to base a judgment regarding this technique.

Comparison with other similar series (Table III) is difficult given the heterogeneity of the different patient populations and the various operative techniques used. Equally as important is personal bias as surgeons often choose the procedures they are most comfortable with.

In conclusion, reoperation with esophageal preservation after a failed antireflux procedure will result in functional benefit in a majority of patients, but functional results deteriorate over time. A reoperation can be done with low mortality and acceptable morbidity. Adherence to basic principles of antireflux surgery should be absolute, and the type of repair should be tailored to the individual patient.

\section{REFERENCES}

1. Skinner DB, Belsey RHR. Surgical management of esophageal reflux and hiatus hernia. J Thorac Cardiovasc Surg 1967;53:33-54.

2. Orringer MB, Skinner DB, Belsey RHR. Long-term results of the Mark IV operation for hiatal hernia and analyses of recurrences and their treatment. J Thorac Cardiovasc Surg 1972;63:25-33.

3. Payne WS. Surgical management of reflux-induced oesophageal stenoses: results in 101 patients. Br J Surg 1984;71: 971-3.

4. Henderson RD, Marryatt G. Recurrent hiatal hernia: management by thoracoabdominal total fundoplication gastroplasty. Can J Surg 1981;24:151-7.

5. Hill LD, Ilves R, Stevenson JK, Pearson JM. Reoperation for disruption and recurrence after Nissen fundoplication. Arch Surg 1979;114:542-8.

6. Leonardi HK, Crozier RE, Ellis FH. Reoperation for complications of the Nissen fundoplication. J Thorac Cardiovasc Surg 1981;81:50-6.

7. Little AG, Ferguson MK, Skinner DB. Reoperation for failed antireflux operations. J Thorac Cardiovasc Surg 1986;91: 511-7.

8. Fékété F, Gayet B, Deslandes M, Dubertret M. Réinterventions pour échec de la chirurgie du reffux gastro-oesophagien. Apropos de cinquante reinterventions. Ann Chir 1992;46:4450 .

9. Siewert JR, Isolauri J, Feussner H. Reoperation following failed fundoplication. World J Surg 1989;13:791-7.

10. Skinner DB. Surgical management after failed antireflux operations. World J Surg 1992;16:359-63.

11. Pearson FG, Cooper JD, Patterson GA, et al. Gastroplasty and fundoplication for complex reflux problems. Ann Surg 1987;206:473-81.

12. Stein HJ, Feussner H, Siewert JR. Failure of antireflux surgery: causes and management strategies. Am J Surg 1996;171:3640.

13. Ellis FH, Gibb SP. Vagotomy, antrectomy, and Roux-en-Y diversion for complex reoperative gastroesophageal refiux disease. Ann Surg 1994;220:536-43.

14. Skinner DB. Esophageal hiatal hernia. The condition: clinical manifestations and diagnosis. In: Sabiston DC Jr, Spencer FC, editors. Surgery of the chest. 5 th ed. Philadelphia: WB Saunders, 1990:890-902.

15. Mehta CR, Patel NR, Tsiatis AA. Exact significance testing for ordered categorical data. Biometrics 1984;40:819-25.

16. Walker SH, Duncan DB. Estimation of the probability of an 
event as a function of several independent variables. $\mathrm{Bi}$ ometrika 1967;54:167-79.

17. Kaplan EL, Meier P. Nonparametric estimation from incomplete observation. J Am Stat Assoc 1958;53:457-81.

18. Peto R, Peto J. Asymptomatically efficient rank invariant procedures (with discussion). J R Statist Soc (series A) 1972;135:185-207.

19. Orringer MB. Management of failed antireflux procedures. In: DeMeester TR, Matthews HR, editors. International trends in general thoracic surgery. Benign esophageal disease. St. Louis, MO: Mosby, 1987:181-204.

20. Skinner DB. Complications of surgery for gastroesphageal reflux. World J Surg 1977;1:485-92.

21. Negre JB. Post-fundoplication symptoms. Do they restrict the success of Nissen fundoplication? Ann Surg 1983;198: 698-700.

22. Kauer WKH, Peters JH, DeMeester TR, et al. A tailored approach to antireflux surgery. J Thorac Cardiovasc Surg 1995;110:141-7.

23. Orringer MB, Orringer JS. The combined Collis-Nissen operation: early assessment of reflux control. Ann Thorac Surg 1982;33:534-9.

24. Allen MS, Trastek VF, Deschamps C, et al. Intrathoracic stomach. Presentation and results of operation. $\mathbf{J}$ Thorac Cardiovasc Surg 1993;105:253-9.

25. Pera M, Deschamps C, Taillefer R, et al. Uncut Collis-Nissen gastroplasty: early functional results. Ann Thorac Surg 1995; 60:915-21.

26. Payne WS. Prevention and treatment of biliary-pancreatic reflux esophagitis: the role of long-limb Roux-Y. Surg Clin North Am 1983:63:851-8.

27. Fékété F, Pateron D. What is the place of antrectomy with Roux-en-Y in the treatment of reflux disease? Experience with 83 total duodenal diversion. World J Surg 1992;16:34954.

28. Waters PF, Pearson FG, Todd TR, et al. Esophagectomy for complex benign disease. J Thorac Cardiovasc Surg 1988;95: 378-81.

29. Weerts JM, Dallemagne B, Hamoir E, et al. Laparoscopic Nissen fundoplication: detailed analysis of 132 patients. Surg Laparosc Endosc 1993;3:357-64.

30. De Paula AL, Hashiba K, Bafutto M, et al. Laparoscopic reoperations after failed and complicated antireflux operations. Surg Endose 1995;9:681-6.

\section{Discussion}

Dr. Andre C. H. Duranceau (Montreal, Quebec, Canada). We must thank Dr. Deschamps and his associates for bringing to our attention a clear and concise summary of their results with a large series of patients reoperated for reflux disease. These patients are always difficult, they require patience, they require a meticulous technique. And, as expected, because the vast majority of those patients had a single operation before, a success rate of over $80 \%$ should be expected with a proper repair.

I have one major preoccupation with your observation, which is based mostly on symptoms. Symptoms in gastroesophageal disease are notoriously inaccurate, and they have been shown by Gibson when trying to correlate them with esophageal mucosal damage to result in a $22 \%$ error margin. And for that reason, it is difficult to accept symptoms either as an indication for surgery or as an estimation of its success.

Today, when assessing esophageal damage from reflux disease, there are four objective measurements that are considered essential to confirm that an operation has been successful in its purpose-that is, to stop the reflux and allow present damage to either stabilize or regress. The addition of endoscopy, histology, reflux documentation by 24-hour $\mathrm{pH}$ studies, and manometric recordings should confirm and could confirm your impression that your excellent control of symptoms in $87 \%$ of patients at 3 months and over time are indeed in correlation with the absence of reflux damage.

Despite these remarks, this is an accurate and honest report on the immediate morbidity and mortality of reoperations.

I have three questions. First, in the stage IV category of patients with a stricture and a columnar-lined esophagus, I would appreciate knowing what your results are in this subgroup, which represents $39 \%$ of your series, and if you came up with a higher incidence of complications and failures. Second, complications were seen in $25 \%$ of your group, and in 12 of these it was a fistula. Could you tell us whether this complication was seen more often with the creation of a gastroplasty, and, if so, their management and results? And finally, in the $25 \%$ of patients with no mucosal damage, those who are expected to have a major functional component to their symptoms, those with no mucosal damage before the operation, what were the indications for their operation and what were their results symptom-wise? Thank you.

Dr. Deschamps. Dr. Duranceau, thank you for your kind comments. That is study spanning more than 30 years. Indeed, not everybody had the test that would give you the extensive evaluation of the disease, and we share your concern that you don't get the whole picture sometimes when you don't do the proper test. Nowadays, in our experience, most of the patients, if not all of the patients, who are evaluated for possible surgery will get endoscopy and a barium swallow and a manometry, and we will get a $\mathrm{pH}$ only in selective patients.

To answer your question about the results in stage IV, actually, in patients with advanced disease of Barrett's or stricture, the results were no different. We try hard to find factors associated with worst result or better result, and we look at each category, including preoperative finding, and the result compared with the rest of the series. There were no more complications with the patient that had Barrett's disease or stricture compared with the patient that had no damage on endoscopy.

Of the 12 patients who had a leak, 6 of the 12 had an uncut Collis-Nissen; two had a Collis-Belsey; one had a Belsey; one, a patient who died, had an antrectomy, and she had a leak through the belly, underwent reoperation, and died because of sepsis and multiple organ failure; and two patients had an abdominal Nissen fundoplication. It seems that adding a gastroplasty might increase their risk in reoperation, but only half of our patients had an uncut Collis-Nissen. Of note, most of those leaks, 11 of 12, did not need reoperation and were treated conservatively with total parenteral nutrition and a longer hospital stay, and they all were healed without further intervention. 
Of the patients who had no damage in their esophagus, the indication for surgery actually was aspiration and pain, most often caused by a paraesophageal recurrence. Those were the indications most of the time in patients with no damage in their esophagus. We do indeed at times operate on patients who have no damage, who have recurrent reflux and don't respond well to medical treatment even if they don't have damage.

Dr. David B. Skinner (New York, N.Y.). That was a very nicely presented and fair assessment of a difficult problem. I guess the question in which I am interested is that, in the failures, you did some resections later, and I presume you excluded resections because this was a series of esophageal-preservation operations. Could you comment about your experience with resections? Your leak rate here of $7 \%$ overall is about what you would expect in the resection series.

Dr. Deschamps. Well, we are looking up our resection series, and I cannot give you the exact numbers, but it is possible that our morbidity will be higher and our leak rate will be higher as well. But I don't have the data on our resection for benign esophageal disease yet. 